\title{
In situ biodegradation, photooxidation and dissolution of petroleum compounds in Arctic seawater and sea ice
}

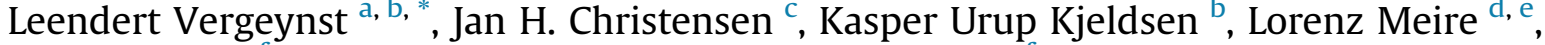 \\ Wieter Boone ${ }^{\mathrm{f}}$, Linus M.V. Malmquist ${ }^{\mathrm{c}}$, Søren Rysgaard ${ }^{\mathrm{a}, \mathrm{f}}$ \\ a Arctic Research Centre, Aarhus University, Aarhus, Denmark \\ b Section for Microbiology and Center for Geomicrobiology, Department of Bioscience, Aarhus University, Aarhus, Denmark \\ ${ }^{\mathrm{c}}$ Department of Plant and Environmental Sciences, Faculty of Science, University of Copenhagen, Copenhagen, Denmark \\ ${ }^{\mathrm{d}}$ Greenland Climate Research Centre, Greenland Institute of Natural Resources, Nuuk, Greenland \\ e Department of Estuarine and Delta Systems, Royal Netherlands Institute of Sea Research, Utrecht University, Yerseke, Netherlands \\ ${ }^{\mathrm{f}}$ Centre for Earth Observation Science, University of Manitoba, Winnipeg, Canada
}

\section{A R T I C L E I N F O}

\section{Article history:}

Received 19 July 2018

Received in revised form

22 October 2018

Accepted 23 October 2018

Available online 29 October 2018

\section{Keywords:}

Oil spill

Biodegradation

Bacterial community

Photooxidation

Arctic

Sea ice

\begin{abstract}
A B S T R A C T
In pristine sea ice-covered Arctic waters the potential of natural attenuation of oil spills has yet to be uncovered, but increasing shipping and oil exploitation may bring along unprecedented risks of oil spills.

We deployed adsorbents coated with thin oil films for up to 2.5 month in ice-covered seawater and sea ice in Godthaab Fjord, SW Greenland, to simulate and investigate in situ biodegradation and photooxidation of dispersed oil.

GC-MS-based chemometric methods for oil fingerprinting were used to identify characteristic signatures for dissolution, biodegradation and photooxidation. In sub-zero temperature seawater, fast degradation of $n$-alkanes was observed with estimated half-life times of $\sim 7$ days. PCR amplicon sequencing and qPCR quantification of bacterial genes showed that a biofilm with a diverse microbial community colonised the oil films, yet a population related to the psychrophilic hydrocarbonoclastic gammaproteobacterium Oleispira antarctica seemed to play a key role in $n$-alkane degradation. Although Oleispira populations were also present in sea ice, we found that biofilms in sea ice had 25 to 100 times lower bacterial densities than in seawater, which explained the non-detectable $n$-alkane degradation in sea ice. Fingerprinting revealed that photooxidation, but not biodegradation, transformed polycyclic aromatic compounds through $50 \mathrm{~cm}$-thick sea ice and in the upper water column with removal rates up to $\sim 1 \%$ per day.

Overall, our results showed a fast biodegradation of $n$-alkanes in sea ice-covered seawater, but suggested that oils spills will expose the Arctic ecosystem to bio-recalcitrant PACs over prolonged periods of time.
\end{abstract}

(c) 2018 Elsevier Ltd. All rights reserved.

\section{Introduction}

A changing climate with reduced seasonal sea ice extent in the Arctic (Barnhart et al., 2016) is opening opportunities for shorter shipping routes (Smith and Stephenson, 2013) and offshore oil exploitation (Gautier et al., 2009), which expose this environment to unprecedented risks of marine oil spills.

Past oil disasters have shown that the natural attenuation

\footnotetext{
* Corresponding author. Arctic Research Centre, Department of Bioscience, Aar hus University, Ny Munkegade 114, building 1540, 8000, Aarhus C, Denmark.

E-mail address: leendert.vergeynst@bios.au.dk (L. Vergeynst).
}

processes evaporation, biodegradation and photooxidation dominate remediation of oil spills and in particular evaporation and biodegradation reduce the environmental impacts (Atlas and Hazen, 2011; Wolfe et al., 1994). This will be no different in the Arctic (Vergeynst et al., 2018). However, physical weathering of oil spills in ice-covered seawater is slow compared to open temperate waters because evaporation is reduced at low temperature (Lee et al., 2015) and oil can get trapped or encapsulated by sea ice (Afenyo et al., 2016). Consequently, biodegradation and photooxidation (when exposed to solar radiation) potentially play an important role to attenuate Arctic oil spills.

Only a limited number of studies have assessed the potential of 
oil biodegradation in Arctic environments. Bacterial communities enriched in microcosms with cold $\left(0-5^{\circ} \mathrm{C}\right)$ seawater from Svalbard and Norway were shown to degrade $n$-alkanes and various polycyclic aromatic compounds (PACs) (Brakstad et al., 2015; Brakstad and Bonaunet, 2006; Ribicic et al., 2018). However, in natural sea ice contaminated with oil on Svalbard, biodegradation was only detectable for $n$-alkanes in the bottom section of the sea ice (Brakstad et al., 2008). Microcosm studies by Kristensen et al. (2015), Scheibye et al. (2017) and Brakstad et al. (2018) with seawater from Disko Bay, W Greenland at $2-5{ }^{\circ} \mathrm{C}$ demonstrated fast biodegradation for $n$-alkanes, alkyltoluenes and the most labile naphthalenes, but contradicting results were obtained for 2 to 4ring PACs. There continues thus to be considerable uncertainty about the potential of natural Arctic microbial communities exposed to low temperature or sea ice to degrade oil compounds, in particular PACs which are among the most toxic oil compounds (Incardona et al., 2013). Furthermore, considering that field information on the in situ degradation potential and identity of key oildegraders is scarce, extrapolating results from ex situ microcosm experiments to the field remains challenging.

Also ultraviolet (UV) radiation-driven photooxidation can transform aromatic compounds in the upper water column (Bacosa et al., 2015), but its role in ice-covered seawater and in sea ice remains unknown. Photooxidation products are generally more polar than their parent compounds, which enhances their dissolution and increases the exposure to marine organisms (Maki et al., 2001; Shemer and Linden, 2007). Furthermore, there may be synergistic effects between photooxidation and biodegradation as photooxidation products are more bioavailable (Garrett et al., 1998) and an enhanced mineralisation has been observed after photooxidation (Dutta and Harayama, 2000).

To study oil biodegradation and the associated bacterial community, photooxidation and dissolution under in situ Arctic conditions, we deployed oil-coated adsorbents for 2.5-month in icecovered seawater and sea ice in Nuup Kangelua (Godthaab Fjord), SW Greenland, located along the Northwest Passage. Thin oil films on these adsorbents mimicked dispersed oil droplets and were colonized by an oil-degrading biofilm. We tailored an advanced chemical fingerprinting technique to acquire insights and disentangle concurrent depletion mechanisms of oil films caused by dissolution, photooxidation and biodegradation. Complementary observations of the bacterial abundance and community composition of oil-biofilms provided insights in the key oil-degraders and explained the differences in the biodegradation potential in seawater and sea ice.

\section{Materials and methods}

\subsection{Field experiment and sampling}

We deployed fluorocarbon-based adsorbents coated with marine gas oil in $50 \mathrm{~cm}$-thick first year sea ice and in the seawater underneath the sea ice in Nuup Kangerlua, SW Greenland $\left(64^{\circ} 26^{\prime} 49^{\prime \prime} \mathrm{N} 51^{\circ} 34^{\prime} 42^{\prime \prime} \mathrm{W}\right)$, for up to 2.5 month during springtime. In February 2016 12.5-cm wide holes were drilled in sea ice using an ice core drill (Kovacs Mark II). In each hole, a polycarbonate half tube (inner diameter $54 \mathrm{~mm}$ ) was installed and contained 4 Fluortex adsorbents (Sefar Inc., production reference 09-250/39, dimensions $90 \times 45 \times 0.29 \mathrm{~mm}$ ) attached by nylon fishing line (Fig. 1). Adsorbents were positioned in the top, middle and bottom of the sea ice and in the underlying seawater (abbreviated T, B, M and SW, Fig. 1). Due to snow accumulation and sea ice melt from the bottom, also B adsorbents were exposed to seawater during most of the time, as illustrated in Fig. 1. Half of the adsorbents where coated on both sides with marine gas oil (Kuwait Petroleum, Denmark) using a paintbrush with nylon bristles. The other half were deployed untreated. Samples of uncoated (controls) and oil-coated adsorbents, as well as seawater and sea ice from around the adsorbents were collected on day 0 and after 31, 51, 63 and 74 days of exposure. At each time point, 4 blank and 4 oil-treated experimental units were drilled out. Seawater from 0 to $50 \mathrm{~cm}$ below the ice was sampled using a Niskin sampler. Ice core sections $(9 \mathrm{~cm}$ diameter) from around the adsorbents, including the adsorbents, were melted in the lab. Adsorbents for chemical analysis were transferred to glass vials with $10 \mathrm{~mL}$ SupraSolv dichloromethane (Merck) and stored in the dark at $4{ }^{\circ} \mathrm{C}$. Adsorbents for microbial analysis were transferred to $50 \mathrm{~mL}$ Falcon centrifuge tubes and stored at $-20{ }^{\circ} \mathrm{C}$. Seawater $(720 \mathrm{~mL})$ and melted ice core sections (127-605 mL) for microbial analysis were filtered over $0.2 \mu \mathrm{m}$ pore size Sterivex filters (Millipore) and stored at $-20^{\circ} \mathrm{C}$. Temperature profiles were recorded in and below the sea ice and ranged from $-1.3{ }^{\circ} \mathrm{C}$ to $+1.6{ }^{\circ} \mathrm{C}$ in the seawater and down to $-3.2{ }^{\circ} \mathrm{C}$ in the sea ice (supplementary information, SI Section 2.1).

\subsection{Gas chromatography - mass spectrometry and chemical fingerprinting}

Samples were purified and dried over $\mathrm{Na}_{2} \mathrm{SO}_{4}$. GC-MS analysis was performed as described by Gallotta and Christensen (2012). In the analytical sequence, a solvent blank (dichloromethane), a marine gas oil reference $\left(20 \mu \mathrm{L} \mathrm{mL}^{-1}\right)$ and a mixture sample of all samples as quality control were analysed after every sixth sample. The sesquiterpane $8 \beta(\mathrm{H})$-homodrimane showed to be conserved under the conditions in this study and was used as an internal standard to quantify depletion of oil compounds from the oil films (SI Section 2.2). A dataset consisting of retention time windows of sections of ion chromatograms (SICs) of $\mathrm{C}_{10-27} n$-alkanes and acyclic isoprenoids and 16 groups of alkylated PACs was compiled (SI Section 1.1 Table S1). The procedure as described by Christensen at al. (2010) was followed to remove variation between SICs that is unrelated to the chemical composition (SI Section 1.1). Briefly, baseline trends were removed by baseline subtraction, SICs were aligned to remove retention time shifts, and changes in detector sensitivity and sample dilution effects were removed by normalisation. PCA was subsequently performed on SICs of $\mathrm{C}_{10-27} n$-alkanes and acyclic isoprenoids and on combined SICs of alkylated PACs. Before PCA, the SICs were centred as such that the mean score values of the initial oil were zero. Hence, the loadings represent the variation in chemical composition between samples and the initial oil.

\subsection{DNA extraction, $q P C R$ and amplicon sequencing of bacterial 165 rRNA genes}

DNA extraction from Sterivex filters was performed using the PowerWater Sterivex DNA Isolation Kit (MO BIO Laboratories). Adsorbents were hung up using fishing line inside a $50 \mathrm{~mL}$ falcon tube and centrifuged for $30 \mathrm{~min}$ at $4700 \times \mathrm{g}$ to recover the biofilm. Separating the pellet of biofilm cells from residual oil was facilitated by addition of $1 \mathrm{~mL}$ sterile filtered phosphate-buffered saline ( $\mathrm{pH} 8$ ). After removing the supernatant, the pellet was suspended in $0.9 \mathrm{~mL}$ of solution ST1B of the DNA isolation kit, transferred to a bead tube and further extracted according to the PowerWater protocol. To quantify bacterial 16S rRNA gene copies, quantitative real-time PCR (qPCR) was performed as described by Starnawski et al. (2017) using the primer pair Bac908F/Bac1075R and SYBR Green-based detection. For PCR amplicon sequencing, fragments covering the V3-V4 region of the 16S rRNA gene were PCR amplified using the primer pair Bac341F/Bac805R (Herlemann et al., 2011). The PCR products were supplied with Illumina 

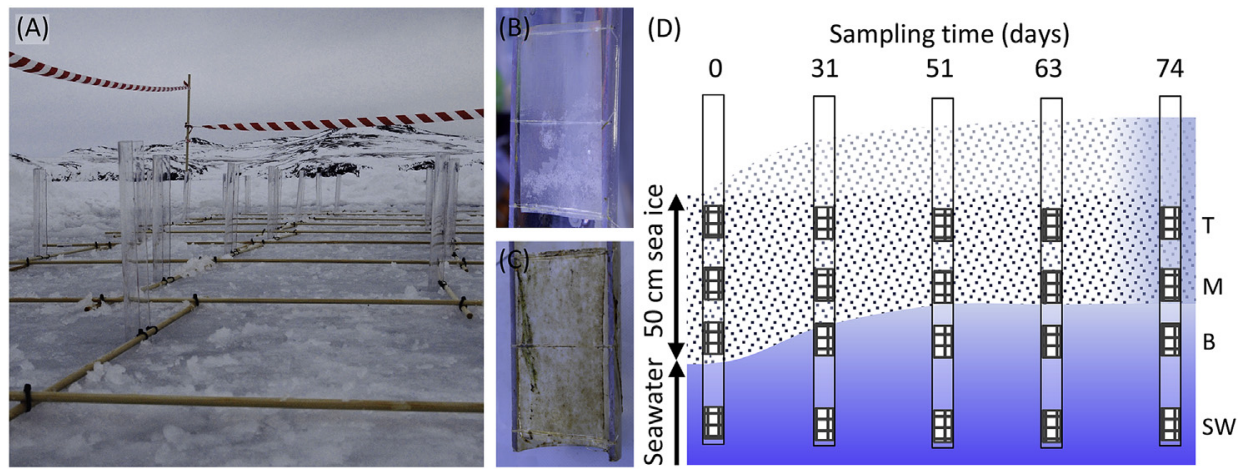

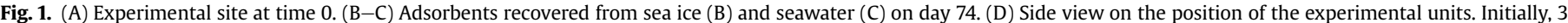

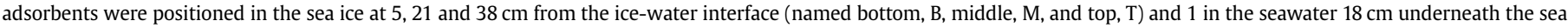
ice (named seawater, SW). Due to snow accumulation and sea ice melt from the bottom, also B adsorbents were exposed to seawater during most of the time.

adaptor overhang sequences in a second PCR. PCR purification, indexing with the Nextera XT Index Kit, library quantification, pooling and sequencing were performed following Illumina's protocol (SI Section 1.2). Pooled libraries were sequenced on an Illumina MiSeq system using a 600 cycle MiSeq v3 Reagent Kit (Illumina) which produces two 300-bp long paired-end reads. Paired-end reads were processed following the MiSeq SOP pipeline using MOTHUR 1.38.1 (SI Section 1.3). Assembled sequences were aligned based on the SILVA SSU Ref NR 99 v123 database, taxonomically classified down to genus level based on the SILVA SSU Reference Taxonomy v123 and clustered into operational taxonomical units (OTUs) based on a $97 \%$ sequence similarity cut-off (SI Section 1.3). Closest relatives having $>97 \%$ sequence similarity were identified from a phylogenetic tree based on the precomputed guide tree of the Silva Living Tree Project ARB database release 123. PCR amplicon sequence data has been deposited at the Sequence Read Archive (https://www.ncbi.nlm.nih.gov/sra) under the BioProject accession SRP150917 and a table containing metadata for each sample, including qPCR results, is provided as supplementary data (SI).

Redundancy analysis was used to summarize the variation in the microbial community composition that could be explained by linear relationships with the environmental variables (SI Section 1.4). Hierarchical complete-linkage clustering analysis was performed to find clusters of OTUs that were enriched and significantly correlated in abundance across samples $(\mathrm{r}>0.8$ and $\mathrm{p}<0.05$; $\mathrm{SI}$ Section 1.5). As distance metric, the pairwise correlation coefficient between log-transformed absolute gene abundances of OTUs over all samples was used. Absolute gene abundances of OTUs were estimated by multiplying the relative gene abundances determined by amplicon sequencing with the total 16S rRNA gene concentration determined by qPCR (SI Section 1.4).

\section{Results and discussion}

\subsection{Mimicking dispersed oil droplets using oil-coated adsorbents}

Using the conservative biomarker sesquiterpane $8 \beta(\mathrm{H})$-homodrimane as internal standard, we quantified that $61-114 \mu \mathrm{L}$ oil was coated on adsorbents (SI Section 2.3). This corresponds to an oil film thickness of 7.4-14 $\mu \mathrm{m}$ (SI Section 2.4). Hence, the oil films had a similar area-to-volume ratio $\left(717-1328 \mathrm{~cm}^{2} \mathrm{~cm}^{-3}\right)$ as spherical oil droplets with a diameter of $45-84 \mu \mathrm{m}$ (SI Section 2.4). These diameters correspond well to the size range of dispersed oil droplets that may be expected in a marine oil spill scenario. Oil droplets with a diameter of less than $50-100 \mu \mathrm{m}$ remain entrained in the water column when breaking waves or chemical dispersants induce dispersion (Li et al., 2017, 2009), or when oil is released from a deep sea wellhead such as during the 2010 Deepwater Horizon disaster in the Gulf of Mexico (North et al., 2011).

Because of their hydrophobic and inert nature, the adsorbents were previously used for investigating hydrocarbon depletion from oil films in static and flow-through laboratory systems (Brakstad et al., 2004; Brakstad and Bonaunet, 2006). Furthermore, considering that (i) biotransformation of oleophilic hydrocarbons is mainly driven by bacteria growing in a biofilm at the oil-water interface (Brakstad and Bonaunet, 2006); (ii) the oil droplet size determines the oil-water interfacial area, which has shown to be a main factor governing biodegradation rates (MacLeod and Daugulis, 2005); and (iii) the oil-coated adsorbents have a similar area-to-volume ratio as dispersed oil droplets; we argue that in situ deployment of oil-coated adsorbents realistically simulates depletion processes of dispersed oil droplets as would occur during an actual oil spill.

\subsection{Disentangling oil depletion processes by quantitative GC-MS analysis and qualitative oil fingerprinting}

Dissolution, photooxidation and biodegradation are the main processes depleting compounds from oil films exposed to sea ice and seawater. We combined GC-MS-based quantitative analysis (Fig. 2) with qualitative fingerprinting (Figs. 3 and 4) of the residual oil on the adsorbents to disentangle these depletion processes. For fingerprinting, we used CHEMSIC (CHEMometric analysis of Sections of Ion Chromatograms), a powerful tool that applies multivariate statistics to pick up signatures that are characteristics for different oil weathering processes (Christensen et al., 2005; Christensen and Tomasi, 2007). This is possible because series of oil compound homologs or isomers have differential susceptibility toward transformation processes such as biodegradation and photooxidation. CHEMSIC analyses all data points in combined sections of GC-MS selected ion chromatograms (SICs) by principal component analysis (PCA). For example, changes in $n C_{17}$-alkane/ pristane and $n \mathrm{C}_{18}$-alkane/phytane ratios are generally used to confirm biodegradation of $n$-alkanes (Wang et al., 1998). Ratios of alkylated PAC isomers that are diagnostic for biodegradation or photooxidation have been used as well (SI Section 2.6 Table S3). While the susceptibility to biodegradation and photooxidation differs within pairs of homologs or isomers, physical processes such as dissolution and evaporation generally affect both members of a pair equally (Wang et al., 1998).

Nearly complete (94-95\%) removal of $\mathrm{C}_{10-27} n$-alkanes was 


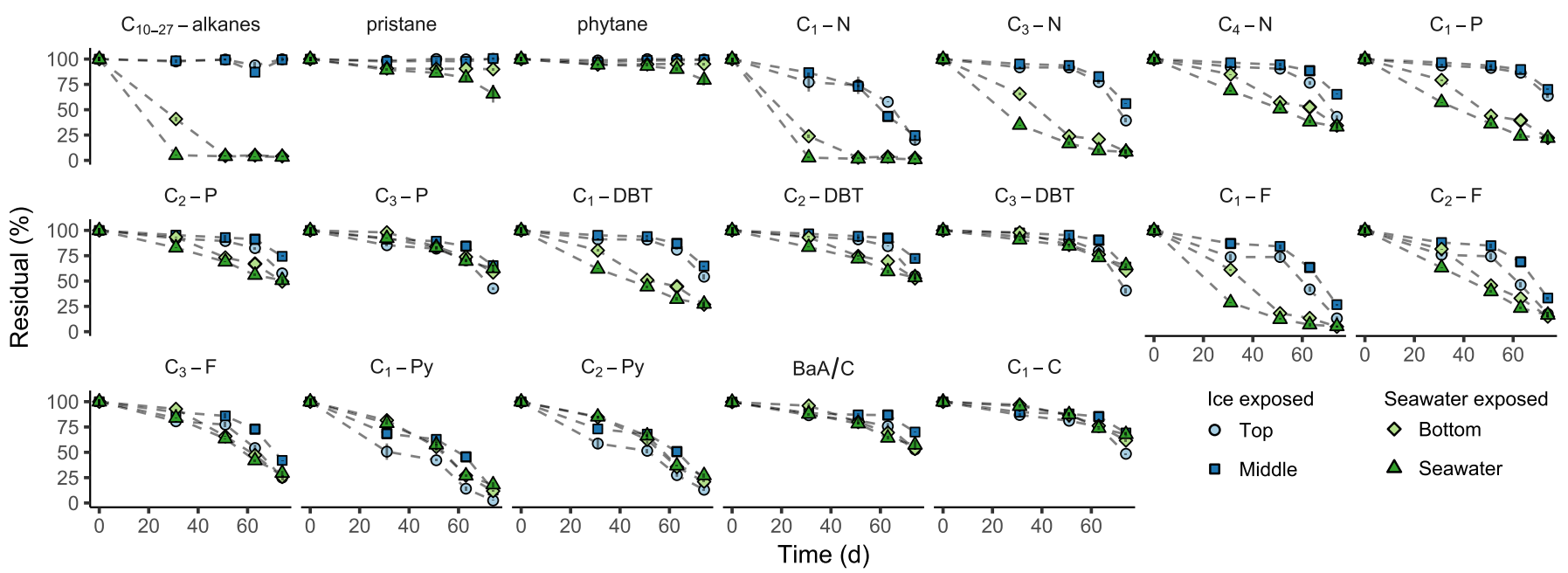

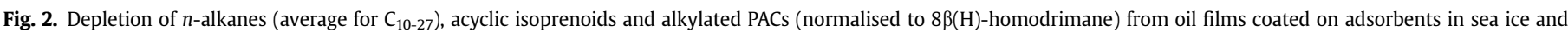
seawater. N: naphthalenes, P: phenanthrenes, DBT: dibenzothiophenes, F: fluorenes, Py: pyrenes, BaA: benzo[a]anthracene, C: chrysenes.

(A)

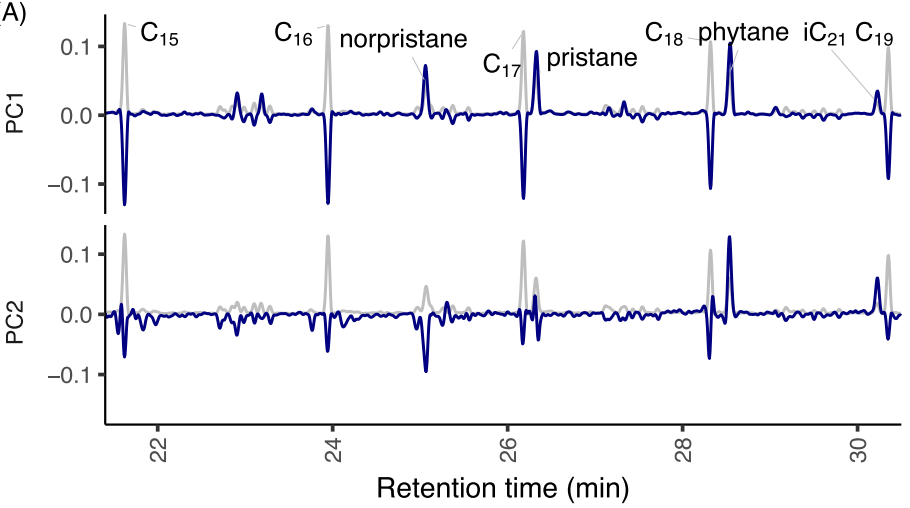

(B)

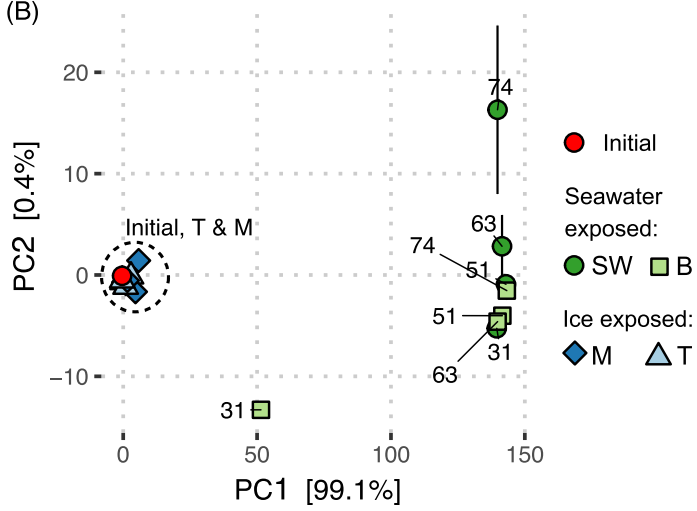

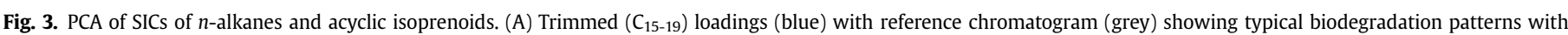

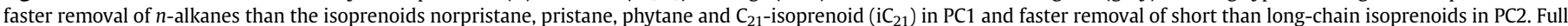

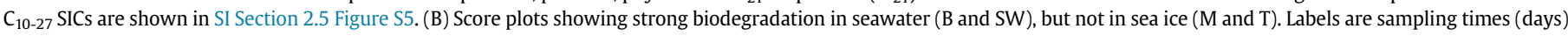

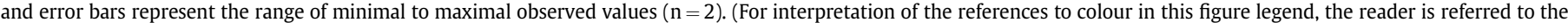
Web version of this article.)

(A)

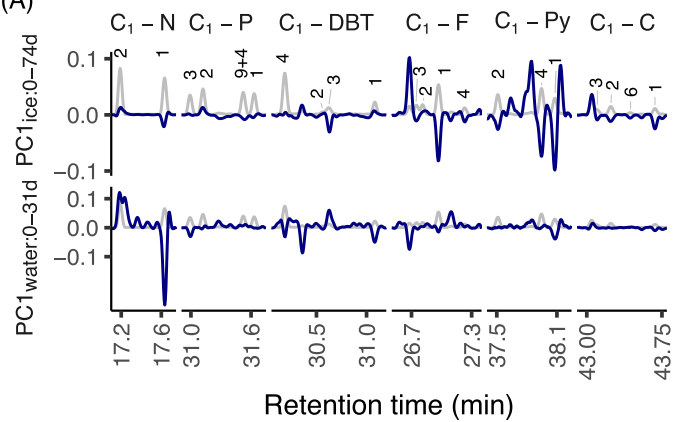

(B)

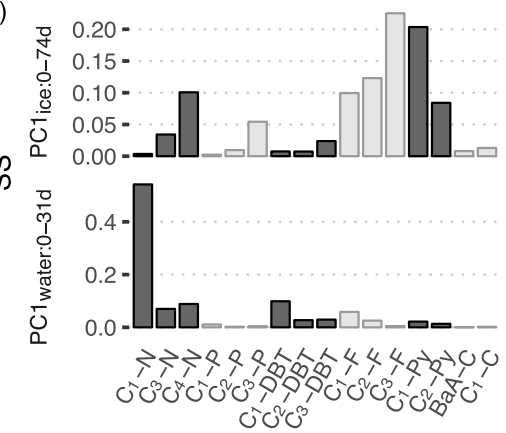

(C)

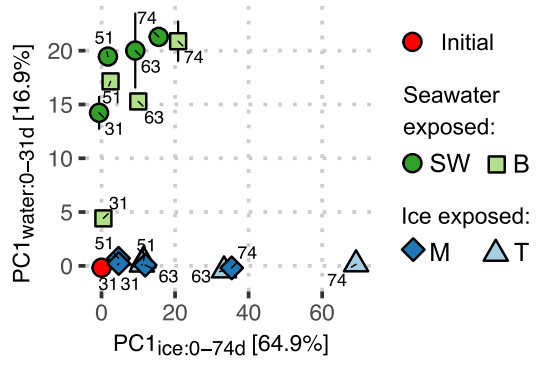

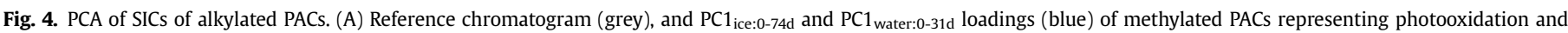

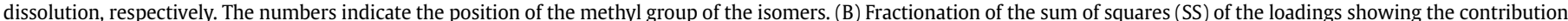

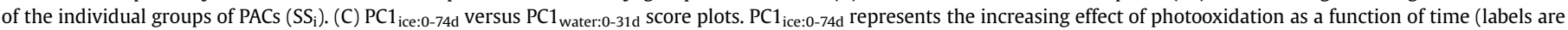

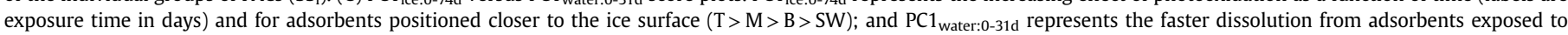

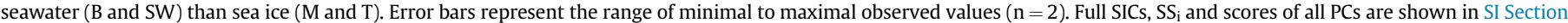
2.6 Figures S6-8. (For interpretation of the references to colour in this figure legend, the reader is referred to the Web version of this article.)

reached within 31 days of exposure of oil-coated adsorbents to seawater (Fig. 2). For the acyclic isoprenoids pristane and phytane, removal efficiencies of $25-42 \%$ and $15-25 \%$, respectively, were observed after 74 days of exposure to seawater. In contrast, these alkanes showed no significant depletion in sea ice. Given that alkanes are practically insoluble in water (Brakstad et al., 2004) and 
resistant to ultraviolet radiation (Garrett et al., 1998), biodegradation was likely the main depletion process affecting the alkane composition during deployment. CHEMSIC on $\mathrm{C}_{10-27}$ alkanes indeed evidenced that the main variation in the chemical fingerprints was caused by biodegradation (Fig. 3A). PC1 explains $99.1 \%$ of the variation and shows a preferential degradation of $\mathrm{C}_{10-27} n$-alkanes over the isoprenoids norpristane, pristane, phytane and $\mathrm{C}_{21}$ isoprenoid as the $n$-alkanes have negative PC1 loading coefficients and the isoprenoids have positive PC1 loading coefficients. This is a well-known indicator for biodegradation of $n$-alkanes (Wang et al., 1998). PC2 loadings describe $0.4 \%$ of the variation and indicate a slightly faster biodegradation of short-chain isoprenoids as compared to longer-chain isoprenoids. The increasing PC1 and PC2 score values in Fig. $3 \mathrm{~B}$ show that biodegradation of $n$-alkanes and isoprenoids increased strongly as a function of time in seawater. The scores also confirm that $n$-alkanes and isoprenoids persisted in ice-exposed samples as these samples clustered with the initial oil in the scores plot. From the measured $85-98 \%$ (on average 95\%) removal of individual $C_{10-27} n$-alkanes over one month (Fig. 2 ), we estimated first-order half-life times of 5.5-11.3 (on average 7.2) days. The substantial in situ $n$-alkane degradation observed in this study confirms results from previous microcosm-based studies of $n$-alkane degradation in seawaters from Greenland and Norway (Brakstad et al., 2018, 2015; Brakstad and Bonaunet, 2006; Kristensen et al., 2015; Scheibye et al., 2017). Similar $n$-alkane biodegradation rates, with half-life times in the order of 1-10 days, were measured in the permanently $\left(4-5^{\circ} \mathrm{C}\right)$ cold deep sea but also in warmer $\left(24^{\circ} \mathrm{C}\right)$ surface waters of the Gulf of Mexico (Hazen et al., 2010; Liu et al., 2017). Biodegradation of $n$-alkanes seems thus not to be limited by the sub-zero temperatures in Arctic seawater, but is strongly limited in sea ice.

Weathering of 16 groups of alkylated PACs followed different patterns in sea ice and seawater, which could not be explained by a single process (Fig. 2). In general, depletion rates of the most watersoluble PACs $\mathrm{C}_{1-4}$-naphthalenes, $\mathrm{C}_{1-2}$-phenanthrenes, $\mathrm{C}_{1-2}$-dibenzothiophenes and $C_{1-2}$-fluorenes were higher in seawater $(43-99 \%$, on average $76 \%$ over 74 day) than in sea ice $(25-89 \%$, on average $53 \%$ over 74 day), and increased for PACs having fewer aromatic rings $(2>3>4$-ring PACs $)$ and fewer alkyl-substitutions $\left(C_{1}>C_{2}>C_{3}>C_{4}\right)$. In contrast, for larger molecular-weight and more alkylated PACs including $\mathrm{C}_{3}$-phenanthrenes, $\mathrm{C}_{3}$-dibenzothiophenes, $C_{3}$-fluorenes, $C_{1-2}$-pyrenes, benzo[a]anthracene/chrysene and $C_{1}$-chrysenes, depletion rates were similar in sea ice and seawater (29-98\%, on average $57 \%$ over 74 days). By sequential CHEMSIC analyses on subsets of samples, we were able to identify orthogonal fingerprints that were characteristic for either photooxidation or dissolution, but not for biodegradation.

A first CHEMSIC trained on ice-exposed samples yielded a PC ( $P C 1_{\text {ice:0-74d }}$ ) that explained the main proportion $(64.9 \%)$ of the total variance. Its loading fingerprint could be identified as a typical photooxidation signature (Fig. 4A). To compare the effect of photooxidation between the 16 groups of PACs, the sum of squares (SS) of the PC1 $1_{\text {ice:0-74d }}$ loading was fractionated to obtain the contributions of each group of PAC isomers $\left(\mathrm{SS}_{\mathrm{i}}\right)$. SICs with a higher $\mathrm{SS}_{\mathrm{i}}$ have a higher weight on the PCA, or in other words their isomers undergo the strongest changes relative to one another. Photooxidation generally increased for PACs with increasing alkylation $\left(\mathrm{C}_{1}<\mathrm{C}_{2}<\mathrm{C}_{3}<\mathrm{C}_{4}\right)$ and with increasing number of aromatic rings (naphthalenes $<$ phenanthrenes and dibenzothiophenes $<$ chrysenes $<$ fluorenes $<$ pyrenes) (Fig. 4B). This agrees with previous observations of PAC photooxidation in surface seawater (Bacosa et al., 2015). Isomer-specific photooxidation patterns observed under laboratory conditions have been reported for methylphenanthrenes, methylpyrenes and methylchrysenes (Bacosa et al. 2015; European Committee for Standardization, 2011; Radović et al., 2014) (SI Section 2.6 Table S3). Similar isomer-specific patterns were found in the $P C 1_{\text {ice:0-74d }}$ patterns. For example, for 1,2 and 4-methylpyrene (MPy), $\mathrm{PC}_{\text {ice:0-74d }}$ shows that photooxidation was faster for 1 than for 4 and 2-methylpyrene ( $1>4>2$-MPy). The latter can be deduced from the loading coefficients that were more negative for 1-MPy followed by 4 and 2-MPy. Photooxidation showed to deplete PACs through $50 \mathrm{~cm}$-thick sea ice and in the underlying seawater (Fig. 4C). The PC1 $1_{\text {ice:0-74d }}$ score values showed that this effect increased as a function of time and for oil-coated adsorbents positioned closer to the ice surface $(\mathrm{T}>\mathrm{M}>\mathrm{B}>\mathrm{SW}$ ) where the UV radiation intensity is highest. Substantial depletion of the larger molecular weight and more alkylated PACs may thus be attributed to photooxidation (Fig. 2). For these compounds, which are otherwise poorly removed by biodegradation or dissolution, we estimated zero-order depletion rates in the range of $0.2-1.1 \%$ per day in sea ice and seawater (SI Section 2.7 Table S4). As far as we know, this study is the first to demonstrate photooxidation of alkylated PACs in sea ice and seawater underneath sea ice. Bacosa et al. (2015) used microcosm experiments to simulate photooxidation in surface seawater under natural light conditions and determined first-order photooxidation half-life times of 1.2-6.9 days for several alkylated PACs (naphthalenes, phenanthrenes, pyrenes and chrysenes). These rates are 1-2 orders of magnitude higher than observed in the present study: the estimated zeroorder depletion rates in the range of $0.2-1.1 \%$ per day imply that it would take $45-250$ days to photo-chemically transform $50 \%$ of the alkylated PACs. Although light transmittance of clean seawater, pure ice and sea ice are similar (Perovich, 1996), the presence of snow cover, particles, algae and coloured dissolved organic matter strongly reduce UV light transmission through sea ice (Kauko et al., 2017), which may explain the lower in situ photooxidation rates reported in the present study.

To identify fingerprints of other removal processes, the photooxidation patterns were removed from the chromatograms of both sea ice and seawater-exposed samples (SI Section 1.1). A second CHEMSIC was then trained on the residuals of the seawaterexposed sample chromatograms with exposure time $\leq 31$ days, yielding $\mathrm{PC} 1_{\text {water:0-31d }}$ explaining $16.9 \%$ of the total variance (Fig. 4A). The PC1 $1_{\text {water:0-31d }}$ fingerprint represented dissolution of methylnaphthalenes and did not correspond to known isomerspecific biodegradation patterns of PACs (SI Section 2.6 Table S3). The negative and positive loading coefficients of the 1- and 2methylnaphthalene isomers, respectively, imply that 1methylnaphthalene was depleted relatively faster than 2methylnaphthalene (Fig. 4A). This is the opposite of the order expected for biodegradation (SI Section 2.6 Table S3), but may be explained by the $5-12 \%$ lower water solubility of the latter isomer (about 191 and $176 \mu \mathrm{M}$ in pure water, respectively) (Pearlman et al., 1984). Considering that only dissolution and no biodegradation fingerprints were detected, the observed 3 to 6.5 times faster depletion of low-molecular weight PACs in seawater than sea ice is thus most likely mainly caused by dissolution (Fig. 2, SI Section 2.7 Table S4). For these compounds, dissolution has been reported to be an important oil film depletion process (Brakstad and Bonaunet, 2006; Scheibye et al., 2017). Faksness and Brandvik (2008) observed that transport of water-soluble compounds in natural sea ice strongly depends on the porosity of the sea ice, which is controlled by temperature and salinity. The slower dissolution in sea ice is thus likely related to the porous structure of sea ice with only 3-26\% brine volume hampering molecular diffusion as well as the high salinity prevailing in the brine pockets (SI Section 2.1 Figure S2), which reduces the aqueous solubility of most PACs (Xie et al., 1997). 


\subsection{Biofilm life style of oil degraders determines microbial community composition and abundance}

We profiled the composition and size of the bacterial communities developing as biofilms on the adsorbents deployed in seawater and sea ice as well as the sea ice communities around the adsorbents by PCR amplicon sequencing and qPCR quantification of 16S rRNA genes. The overall community composition in oil-treated and untreated samples is presented in SI Section 2.8 Figure S9. Redundancy analysis in combination with correlation-based hierarchical clustering revealed the presence of 12 clusters of correlated operational taxonomical units (OTUs) being the most strongly enriched in oil-treated samples as compared to controls (SI Sections 2.9 and 2.10). The 12 clusters included a total of 60 enriched OTUs. The change of abundance over time of the OTUs within each cluster was significantly correlated $(\mathrm{p}<0.05)$ with pairwise correlation coefficients of at least $0.8(\mathrm{r}>0.8)$. The larger proportion of the 12 clusters in oil-treated ( $62 \pm 22 \%$ of 16 rRNA genes) as compared to control samples $(11 \pm 8 \%)$ confirms their association with oil (Fig. 5 and SI Section 2.10 Figure S13). Several among these taxa were previously associated to oil biodegradation (SI Section 2.11 Table S5). The distinct clusters either consisted of taxa of the class Flavobacteriia along with a few $\alpha$ - and $\gamma$-Proteobacteria, or the classes $\gamma$-, $\delta$ - and $\varepsilon$-Proteobacteria (Fig. 6A). These consistent intracluster phylogenetic affiliations indicate that the clusters reflected ecological associations. In SI Section 2.10, we discuss the relations between the clusters and their environment in detail.

Fast oil-induced microbial community dynamics occurred during the first 31 days concurrent with a drastic increase of the total bacterial abundance (Figs. 5 and 7). These community shifts were driven by an exponential increase of mainly the OTU clusters $1,3,4$ and 8 in seawater and sea ice (Fig. 6B-D). Cluster 1 consisted mainly of an OTU having $99.1 \%$ sequence identity to the psychrophilic obligate hydrocarbonoclastic alkane-degrading Oleispira antarctica (Yakimov et al., 2003). As the only known obligate hydrocarbon degrader (i.e. degrading only hydrocarbons and their derivatives) detected by the community profiling, 0 . antarctica (Yakimov et al., 2003) was likely responsible for the effective $n$ alkane degradation in seawater during the first 31 days (Fig. 2).
Furthermore, the taxa in the clusters 3, 4 and 8 (Colwellia, Peredibacter, Bacteriovorax and Arcobacter), are not known to degrade $n$-alkanes, but have been related to oil contamination and could potentially degrade low-molecular weight aromatic compounds such as benzene and phenanthrene (Ding et al., 2012; Hu et al., 2017; Prabagaran et al., 2007; Redmond and Valentine, 2011; Yakimov et al., 2004). Abundances of these taxa increased by up to $\sim 10000$ and 100000 fold in response to oil exposure in sea ice and seawater, respectively (Fig. 6C). As a result of these exponential increases, the total number of bacterial gene copies observed on oilcoated adsorbents at day 31 was about 10-700-fold higher than on controls (Fig. 7). Biofilm formation on absorbents exposed to seawater was 25-100 times more extensive than on those exposed to sea ice. In the sea ice around the oil-coated adsorbents, bacterial abundances increased only 5 -fold as compared to control sea ice (day 31-63).

The 25 to 100 times lower bacterial abundance in the oil biofilms exposed to sea ice as compared to seawater likely explains the lacking biodegradation of $n$-alkanes in sea ice. The porous structure of sea ice (SI Section 2.1 Figure S2) implies that only a small fraction of the surface area of the oil films was in direct contact with brine (oil-brine interface). Brine is the phase in which sea ice microorganisms proliferate (Junge et al., 2004). Given that $n$-alkanes are practically insoluble in water (Brakstad et al., 2004) and that biodegradation of $n$-alkanes has been shown to be a solely biofilmmediated process (Brakstad and Bonaunet, 2006), the limited oilbrine interfacial area in sea ice likely prevented the development of a sufficiently abundant oil-degrading biofilm resulting in a nondetectable removal of $n$-alkanes.

Between day 31 and 71, OTU clusters 1, 3, 4 and 8 generally decreased in relative abundance (Figs. 5 and 6D). In seawater, this may be explained by substrate depletion of the most labile and water-soluble oil compounds due to biodegradation (e.g., n-alkanes) and dissolution (e.g., naphthalenes), respectively (Fig. 2). Concurrently, several other OTU clusters started proliferating, potentially in response to biodegradation of more recalcitrant oil compounds. In particular cluster 10 , consisting mainly of members of the class Flavobacteriia, increased in abundance as a function of time in oil-biofilms exposed to seawater. The Flavobacteriia genus

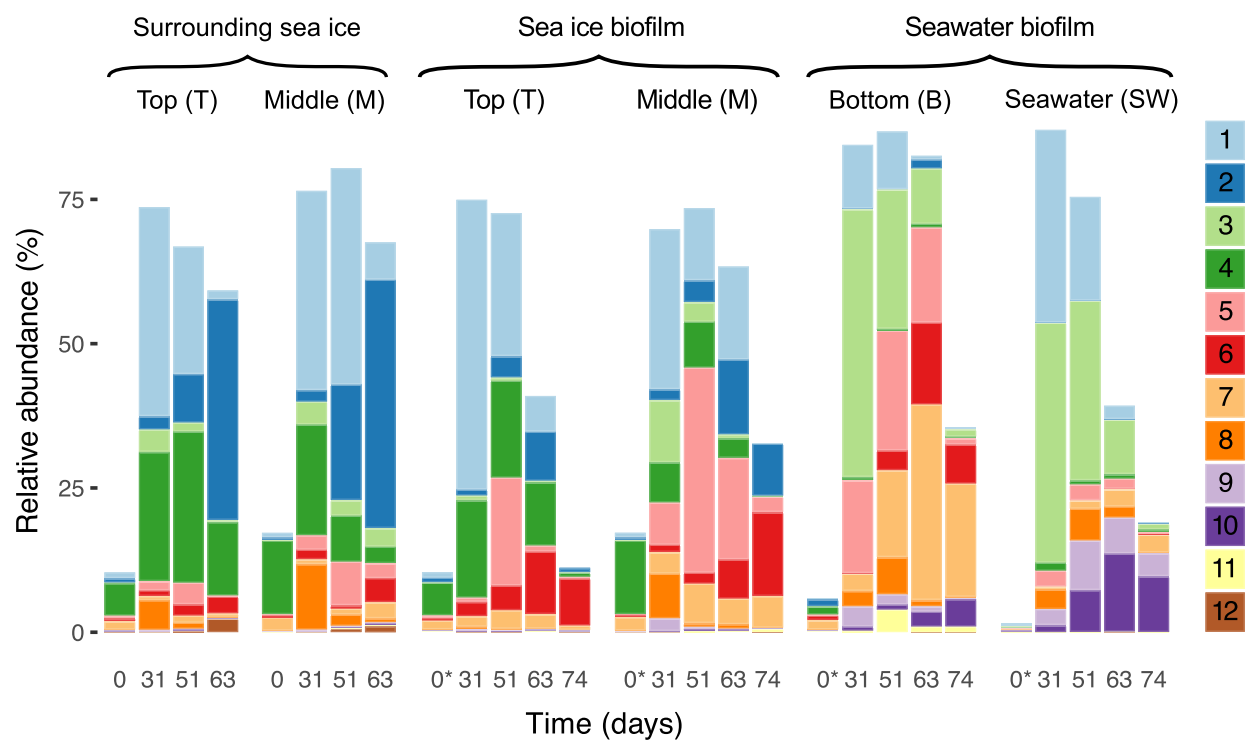

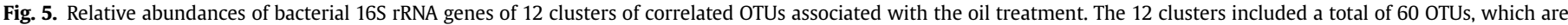

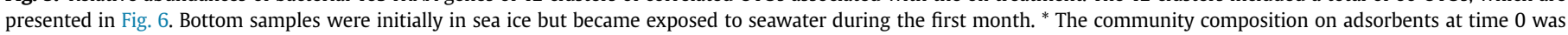

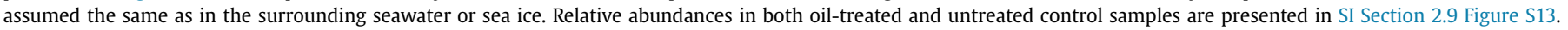




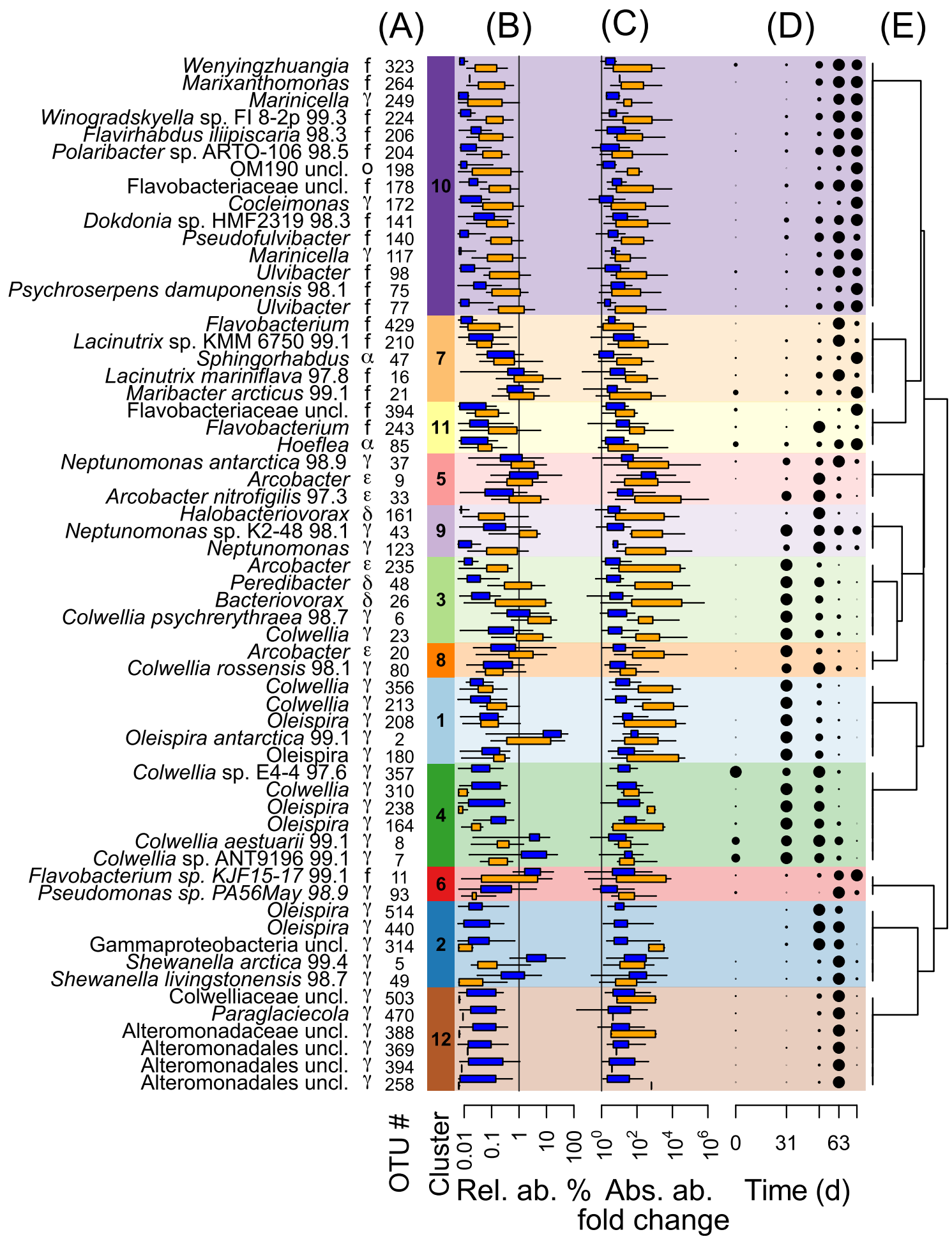

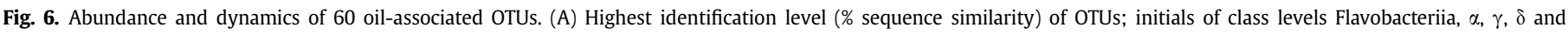

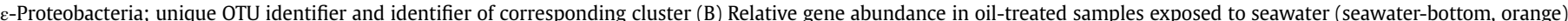

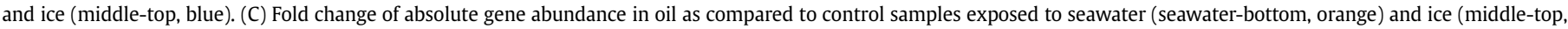

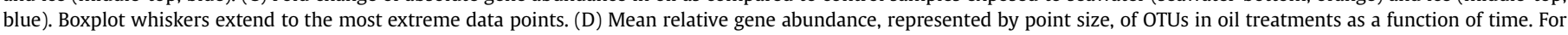

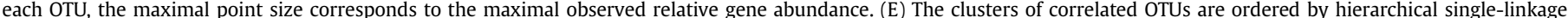

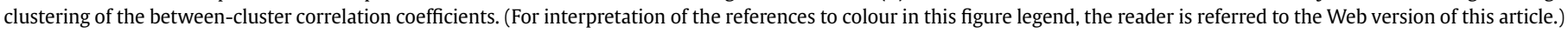

Winogradskyella has been associated to degradation of branched alkanes (Wang et al., 2016) and may thus be responsible for the observed degradation of branched alkanes such as acyclic isoprenoids between day 31 and 74 (Fig. 2). The other genera
Dokdonia, Polaribacter, Pseudofulvibacter and Ulvibacter of cluster 10 have also been associated to oil pollution, but their function remain unclear (Alonso-Gutiérrez et al., 2008; Brakstad et al., 2018; Gerdes et al., 2005; Krolicka et al., 2017; Prabagaran et al., 2007). Clusters 

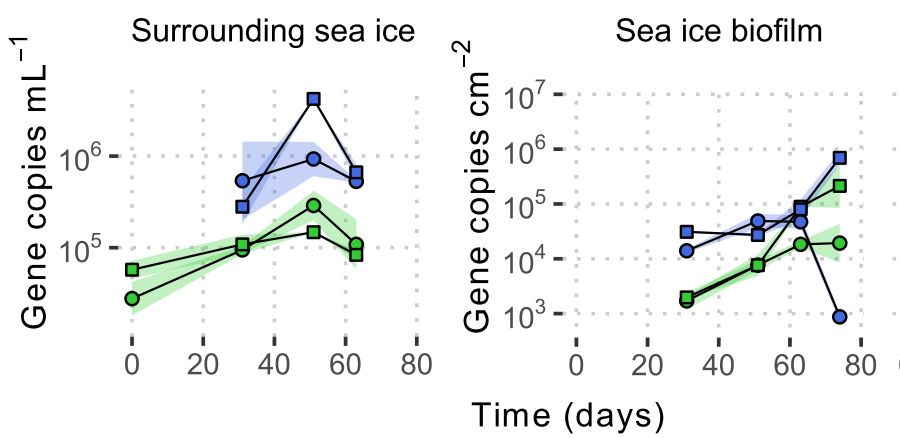

Seawater biofilm

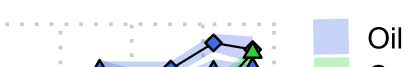

Oil
Contro

- Top (T)

口 Middle (M)

$\diamond$ Bottom (B)

$\triangle$ Seawater (SW)

Time (days)

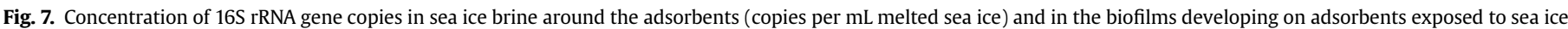
and seawater (copies per $\mathrm{cm}^{2}$ adsorbent). The symbols represent geometric mean values and the ribbons cover the range of minimal to maximal observed values ( $\mathrm{n}=2$ ).

5-7, 9 and 11 consisted of members of the genera Flavobacterium, Neptunomonas and Pseudomonas, which are known for their capabilities to degrade various 2 to 4-ring PACs (Hedlund et al., 1999; Trzesicka-Mlynarz and Ward, 1995; Wang et al., 2008), Sphingorhabdus, possessing aliphatic and aromatic hydrocarbon-catalysing genes (Jeong et al., 2016), and Hoeflea, able to grow on diesel (Rahul et al., 2015). Despite the sufficient growth to turn over the microbial community and presence of potential PAC degraders, no chemical fingerprints for PAC biodegradation were detected (Fig. 4). However, the applied chemical analyses cannot account for biodegradation occurring in the dissolved phase, i.e. after dissolution of water-soluble PACs and away from the oil-water interface in the surrounding seawater. Biodegradation of the most water-soluble PACs such as methylnaphthalenes may thus have occurred in the water-phase as also shown by studies with subsurface seawaters from Disko Bay, W Greenland (Kristensen et al., 2015; Scheibye et al., 2017). As in the present study, the latter studies did not observe biodegradation of 3 to 4-ring PACs. Considering that the fraction of biodegradation taking place at the oil-water interface increases for more oleophilic PACs (Brakstad and Bonaunet, 2006), an overall low PAC biodegradation potential can be concluded for the investigated seawaters. However, further research is required to better understand the parameters controlling PAC biodegradation in the Arctic, as a study by Brakstad et al. (2018) with seawater from Disko Bay, SW Greenland, and several other studies from the Norwegian and Canadian Arctic (Garneau et al., 2016; McFarlin et al., 2014; Ribicic et al., 2018) have shown a potential for biodegradation of 2 to 4 -ring PACs.

In sea ice, the succession of the microbial community composition between day 31 and 63 may have been a response to exposure to water-soluble oil compounds as the decreasing abundance of clusters 4 and 8 in the biofilm concurred with the dissolution of PACs (Fig. 2). Over time, $O$. antarctica (cluster 1 ) was replaced by the psychrophilic $n$-alkane-degrading Shewanella arctica and Shewanella livingstonensis of cluster 2 (Gentile et al., 2003; Gerdes et al., 2005) (Fig. 5). This may suggest that Shewanella was better adapted than Oleispira to grow on $n$-alkanes in sea ice.

Between day 63 and 74, the melting of the sea ice left a surface layer of fresh water. This event likely caused the strong decreases in biofilm abundance in adsorbents positioned in the top of the sea ice at day 74 (Fig. 7 ).

\section{Conclusions}

In situ deployments of oil-coated adsorbents in sea ice and seawater in SW Greenland provided a complete picture of photooxidation, biodegradation and dissolution at oil-water interfaces. We linked chemical degradation patterns to key players in the oilassociated bacterial community. Our study led to the following key results: UV showed to photo-oxidize photosensitive PACs through $50 \mathrm{~cm}$ thick sea ice and in the underlying seawater. Dissolution removed water-soluble oil compounds such as PACs at 3-6.5 times faster rates in seawater than in sea ice. Biofilms colonizing the oil films showed to be essential for effective oil biodegradation. Oleispira antarctica inhabiting the biofilms was identified as a key $n$-alkane degrader removing $n$-alkanes in sub-zero temperature seawater at similar rates as in temperate climates. However, the porous structure of sea ice limited biofilm development resulting in non-detectable $n$-alkane degradation in sea ice. In addition to $n$ alkane degraders, potential degraders of mono aromatic compounds and PACs colonized the oil biofilms. Despite the presence of potential PAC degraders, observed chemical fingerprints could not reveal PAC biodegradation.

Given the environmental context characterised by a dark Arctic winter, sea ice cover and the weak intensity of ultraviolet light in subsurface seawater, the low in situ biodegradation potential of polycyclic aromatic compounds over 2.5 month is an alarming discovery.

\section{Acknowledgements}

Britta Poulsen, Susanne Nielsen and Trine B. Søgaard from Bioscience, Aarhus University, are gratefully acknowledged for the excellent technical laboratory assistance. This work is a contribution to the Arctic Science Partnership (asp-net.org) and was supported by the research grant 17454 from Villum Fonden and the Arctic Research Centre (ARC) at Aarhus University.

\section{Appendix A. Supplementary data}

Supplementary data to this article can be found online at https://doi.org/10.1016/j.watres.2018.10.066.

\section{References}

Afenyo, M., Veitch, B., Khan, F., 2016. A state-of-the-art review of fate and transport of oil spills in open and ice-covered water. Ocean Eng. 119, 233-248. https:// doi.org/10.1016/j.oceaneng.2015.10.014.

Alonso-Gutiérrez, J., Costa, M.M., Figueras, A., Albaigés, J., Viñas, M., Solanas, A.M. Novoa, B., 2008. Alcanivorax strain detected among the cultured bacterial community from sediments affected by the 'Prestige' oil spill. Mar. Ecol. Prog. Ser. 362, 25-36. https://doi.org/10.3354/meps07431.

Atlas, R.M., Hazen, T.C., 2011. Oil biodegradation and bioremediation: a tale of the two worst spills in U.S. history. Environ. Sci. Technol. 45, 6709-6715. https:// doi.org/10.1021/es2013227.

Bacosa, H.P., Erdner, D.L., Liu, Z., 2015. Differentiating the roles of photooxidation and biodegradation in the weathering of Light Louisiana Sweet crude oil in surface water from the Deepwater Horizon site. Mar. Pollut. Bull. 95, 265-272. https://doi.org/10.1016/j.marpolbul.2015.04.005.

Barnhart, K.R., Miller, C.R., Overeem, I., Kay, J.E., 2016. Mapping the future expansion of Arctic open water. Nat. Clim. Change 6, 280-285. https://doi.org/10.1038/ nclimate 2848. 
Brakstad, O.G., Bonaunet, K., 2006. Biodegradation of petroleum hydrocarbons in seawater at low temperatures $\left(0-5{ }^{\circ} \mathrm{C}\right)$ and bacterial communities associated with degradation. Biodegradation 17, 71-82. https://doi.org/10.1007/s10532 005-3342-8.

Brakstad, O.G., Bonaunet, K., Nordtug, T., Johansen, Ø., 2004. Biotransformation and dissolution of petroleum hydrocarbons in natural flowing seawater at low temperature. Biodegradation 15, 337-346. https://doi.org/10.1023/B: BIOD.0000042189.69946.07.

Brakstad, O.G., Davies, E.J., Ribicic, D., Winkler, A., Brönner, U., Netzer, R., 2018 Biodegradation of dispersed oil in natural seawaters from Western Greenland and a Norwegian fjord. Polar Biol. https://doi.org/10.1007/s00300-018-2380-8.

Brakstad, O.G., Nonstad, I., Faksness, L.-G., Brandvik, P.J., 2008. Responses of microbial communities in Arctic sea ice after contamination by crude petroleum oil. Microb. Ecol. 55, 540-552. https://doi.org/10.1007/s00248-007-9299-X.

Brakstad, O.G., Throne-Holst, M., Netzer, R., Stoeckel, D.M., Atlas, R.M., 2015. Microbial communities related to biodegradation of dispersed Macondo oil at low seawater temperature with Norwegian coastal seawater. Microb. Biotechnol. 8 , 989-998. https://doi.org/10.1111/1751-7915.12303.

Christensen, J.H., Tomasi, G., 2007. Review. Practical aspects of chemometrics for oil spill fingerprinting. J. Chromatogr. A 1169, 1-22. https://doi.org/10.1016 j.chroma.2007.08.077.

Christensen, J.H., Tomasi, G., Hansen, A.B., 2005. Chemical fingerprinting of petroleum biomarkers using time warping and PCA. Environ. Sci. Technol. 39, 255-260. https://doi.org/10.1021/es049832d.

Christensen, J.H., Tomasi, G., Scofield, A.D.L., Meniconi, M.D.F.G., 2010. A novel approach for characterization of polycyclic aromatic hydrocarbon (PAH) pollution patterns in sediments from Guanabara Bay, Rio de Janeiro, Brazil. Environ. Pollut. 158, 3290-3297. https://doi.org/10.1016/j.envpol.2010.07.015.

Ding, G.-C., Heuer, H., Smalla, K., 2012. Dynamics of bacterial communities in two unpolluted soils after spiking with phenanthrene: soil type specific and common responders. Front. Microbiol. 3, 1-16. https://doi.org/10.3389/ fmicb.2012.00290.

Dutta, T.K., Harayama, S., 2000. Fate of crude oil by the combination of photooxidation and biodegradation. Environ. Sci. Technol. 34, 1500-1505. https:/ doi.org/10.1021/es991063o.

European Committee for Standardization, 2011. CEN/TR 15522-2, Oil Spill Identification - Waterborne Petroleum and Petroleum Products - Part 2: Analytica Methodology and Interpretation of Results Based on GC-FID and GC-MS Low Resolution Analyses.

Faksness, L.-G., Brandvik, P.J., 2008. Distribution of water soluble components from oil encapsulated in Arctic sea ice: summary of three field seasons. Cold Reg. Sci. Technol. 54, 106-114. https://doi.org/10.1016/j.coldregions.2008.03.006.

Gallotta, F.D.C., Christensen, J.H., 2012. Source identification of petroleum hydrocarbons in soil and sediments from Iguaçu River Watershed, Paraná, Brazil using the CHEMSIC method (CHEMometric analysis of Selected Ion Chromatograms) J. Chromatogr. A 1235, 149-158. https://doi.org/10.1016/j.chroma.2012.02.041.

Garneau, M.-È., Michel, C., Meisterhans, G., Fortin, N., King, T.L., Greer, C.W., Lee, K. 2016. Hydrocarbon biodegradation by Arctic sea-ice and sub-ice microbia communities during microcosm experiments, Northwest Passage (Nunavut, Canada). FEMS Microbiol. Ecol. 92, fiw130. https://doi.org/10.1093/femsec fiw130.

Garrett, R.M., Pickering, I.J., Haith, C.E., Prince, R.C., 1998. Photooxidation of crude oils. Environ. Sci. Technol. 32, 3719-3723. https://doi.org/10.1021/es980201r.

Gautier, D.L., Bird, K.J., Charpentier, R.R., Grantz, A., Houseknecht, D.W., Klett, T.R. Moore, T.E., Pitman, J.K. Schenk, C.J., Schuenemeyer, J.H., Sorensen, K Tennyson, M.E., Valin, Z.C., Wandrey, C.J., 2009. Assessment of undiscovered oil and gas in the arctic. Science (80-. ) 324, 1175-1179. https://doi.org/10.1126 science.1169467.

Gentile, G., Bonasera, V., Amico, C., Giuliano, L., Yakimov, M.M., 2003. Shewanella sp. GA-22, a psychrophilic hydrocarbonoclastic antarctic bacterium producing polyunsaturated fatty acids. J. Appl. Microbiol. 95, 1124-1133. https://doi.org 10.1046/j.1365-2672.2003.02077x.

Gerdes, B., Brinkmeyer, R., Dieckmann, G., Helmke, E., 2005. Influence of crude oil on changes of bacterial communities in Arctic sea-ice. FEMS Microbiol. Ecol. 53, 129-139. https://doi.org/10.1016/j.femsec.2004.11.010.

Hazen, T.C., Dubinsky, E. a, DeSantis, T.Z., Andersen, G.L., Piceno, Y.M., Singh, N. Jansson, J.K., Probst, A., Borglin, S.E., Fortney, J.L., Stringfellow, W.T., Bill, M., Conrad, M.E., Tom, L.M., Chavarria, K.L., Alusi, T.R., Lamendella, R., Joyner, D.C. Spier, C., Baelum, J., Auer, M., Zemla, M.L., Chakraborty, R., Sonnenthal, E.L. D'haeseleer, P., Holman, H.-Y.N., Osman, S., Lu, Z., Van Nostrand, J.D., Deng, Y, Zhou, J., Mason, O.U., 2010. Deep-sea oil plume enriches indigenous oildegrading bacteria. Science (80-. ) 330, 204-208. https://doi.org/10.1126/ science.1195979.

Hedlund, B.P., Geiselbrecht, A.D., Bair, T.J., Staley, J.T., 1999. Polycyclic aromatic hydrocarbon degradation by a new marine bacterium, Neptunomonas naphthovorans gen. nov., sp. nov. Appl. Environ. Microbiol. 65, 251-259.

Herlemann, D.P., Labrenz, M., Jürgens, K., Bertilsson, S., Waniek, J.J., Andersson, A.F., 2011. Transitions in bacterial communities along the $2000 \mathrm{~km}$ salinity gradien of the Baltic Sea. ISME J. 5, 1571-1579. https://doi.org/10.1038/ismej.2011.41.

Hu, P., Dubinsky, E.A., Probst, A.J., Wang, J., Sieber, C.M.K., Tom, L.M., Gardinali, P.R., Banfield, J.F., Atlas, R.M., Andersen, G.L., 2017. Simulation of Deepwater Horizon oil plume reveals substrate specialization within a complex community of hydrocarbon degraders. Proc. Natl. Acad. Sci. Unit. States Am. 114, 7432-7437. https://doi.org/10.1073/pnas.1703424114.

Incardona, J.P., Swarts, T.L., Edmunds, R.C., Linbo, T.L., Aquilina-Beck, A., Sloan, C.A.
Gardner, L.D., Block, B.A., Scholz, N.L., 2013. Exxon Valdez to Deepwater Horizon: comparable toxicity of both crude oils to fish early life stages. Aquat. Toxicol. 142-143, 303-316. https://doi.org/10.1016/j.aquatox.2013.08.011.

Jeong, H.I., Jin, H.M., Jeon, C.O., 2016. Complete genome sequence of Sphingorhabdus sp. M41, a versatile hydrocarbon degrader, isolated from crude oilcontaminated costal sediment. J. Biotechnol. 227, 41-42. https://doi.org/ 10.1016/j.jbiotec.2016.04.016.

Junge, K., Eicken, H., Deming, J.W., 2004. Bacterial Activity at -2 to -20 degrees $C$ in Arctic wintertime sea ice. Appl. Environ. Microbiol. 70, 550-557. https:// doi.org/10.1128/AEM.70.1.550.

Kauko, H.M., Taskjelle, T., Assmy, P., Pavlov, A.K., Mundy, C.J., Duarte, P., FernándezMéndez, M., Olsen, L.M., Hudson, S.R., Johnsen, G., Elliott, A., Wang, F., Granskog, M.A., 2017. Windows in Arctic sea ice: light transmission and ice algae in a refrozen lead. J. Geophys. Res. Biogeosciences 122, 1486-1505. https://doi.org/10.1002/2016JG003626.

Kristensen, M., Johnsen, A.R., Christensen, J.H., 2015. Marine biodegradation of crude oil in temperate and Arctic water samples. J. Hazard Mater. 300, 75-83. https://doi.org/10.1016/j.jhazmat.2015.06.046.

Krolicka, A., Boccadoro, C., Nilsen, M.M., Baussant, T., 2017. Capturing early changes in the marine bacterial community as a result of crude oil pollution in a mesocosm experiment. Microb. Environ. 32, 358-366. https://doi.org/10.1264/ jsme2.ME17082.

Lee, K., Boufadel, M.C., Chen, B., Foght, J., Hodson, P., Swanson, S., Venosa, A.D., 2015 The Behaviour and Environmental Impacts of Crude Oil Released into Aqueous Environments. Royal Society of Canada, Ottawa, ON.

Li, Z., Lee, K., King, T., Boufadel, M.C., Venosa, A.D., 2009. Evaluating crude oil chemical dispersion efficacy in a flow-through wave tank under regular nonbreaking wave and breaking wave conditions. Mar. Pollut. Bull. 58, 735-744. https://doi.org/10.1016/j.marpolbul.2008.12.014.

Li, Z., Spaulding, M.L., French-McCay, D., 2017. An algorithm for modeling entrainment and naturally and chemically dispersed oil droplet size distribution under surface breaking wave conditions. Mar. Pollut. Bull. 119, 145-152. https:// doi.org/10.1016/j.marpolbul.2017.03.048.

Liu, J., Bacosa, H.P., Liu, Z., 2017. Potential environmental factors affecting oildegrading bacterial populations in deep and surface waters of the northern Gulf of Mexico. Front. Microbiol. 7, 1-14. https://doi.org/10.3389/ fmicb.2016.02131.

MacLeod, C.T., Daugulis, A.J., 2005. Interfacial effects in a two-phase partitioning bioreactor: degradation of polycyclic aromatic hydrocarbons (PAHs) by a hydrophobic Mycobacterium. Process Biochem. 40, 1799-1805. https://doi.org/ 10.1016/j.procbio.2004.06.042.

Maki, H., Sasaki, T., Harayama, S., 2001. Photo-oxidation of biodegraded crude oil and toxicity of the photo-oxidized products. Chemosphere 44, 1145-1151. https://doi.org/10.1016/S0045-6535(00)00292-7.

McFarlin, K.M., Prince, R.C., Perkins, R., Leigh, M.B., 2014. Biodegradation of dispersed oil in arctic seawater at $-1^{\circ} \mathrm{C}$. PLoS One 9, e84297. https://doi.org/ 10.1371/journal.pone.0084297.

North, E.W., Adams, E.E., Schlag, Z., Sherwood, C.R., He, R., Hyun, K.H., Socolofsky, S.A., 2011. Simulating oil droplet dispersal from the deepwater Horizon spill with a Lagrangian approach. In: Monitoring and Modeling the Deepwater Horizon Oil Spill: a Record-breaking Enterprise, pp. 217-226. https://doi.org/10.1029/2011GM001102.

Pearlman, R.S., Yalkowsky, S.H., Banerjee, S., 1984. Water solubilities of polynuclear aromatic and heteroaromatic compounds. J. Phys. Chem. Ref. Data 13, 555-562. https://doi.org/101063/1.555712.

Perovich, D.K., 1996. Optical Properties of Sea Ice.

Prabagaran, S.R., Manorama, R., Delille, D., Shivaji, S., 2007. Predominance of roseobacter, sulfitobacter, glaciecola and psychrobacter in seawater collected off ushuaia, Argentina, sub-Antarctica. FEMS Microbiol. Ecol. 59, 342-355. https:// doi.org/10.1111/j.1574-6941.2006.00213.x.

Radović, J.R., Aeppli, C., Nelson, R.K., Jimenez, N., Reddy, C.M., Bayona, J.M., Albaigés, J., 2014. Assessment of photochemical processes in marine oil spill fingerprinting. Mar. Pollut. Bull. 79, 268-277. https://doi.org/10.1016/ j.marpolbul.2013.11.029.

Rahul, K., Azmatunnisa, M., Sasikala, C.H., Ramana, C.V., 2015. Hoeflea olei sp. Nov., a diesel-oil-degrading, anoxygenic, phototrophic bacterium isolated from backwaters and emended description of the genus Hoeflea. Int. J. Syst. Evol. Microbiol. 65, 2403-2409. https://doi.org/10.1099/ijs.0.000277.

Redmond, M.C., Valentine, D.L., 2011. Science applications in the deepwater Horizon oil spill special feature: natural gas and temperature structured a microbial community response to the deepwater Horizon oil spill. Proc. Natl. Acad. Sci. Unit. States Am. https://doi.org/10.1073/pnas.1108756108.

Ribicic, D., Netzer, R., Winkler, A., Brakstad, O.G., 2018. Microbial communities in seawater from an Arctic and a temperate Norwegian fjord and their potentials for biodegradation of chemically dispersed oil at low seawater temperatures. Mar. Pollut. Bull.129, 308-317. https://doi.org/10.1016/j.marpolbul.2018.02.024.

Scheibye, K., Christensen, J.H., Johnsen, A.R., 2017. Biodegradation of crude oil in Arctic subsurface water from the Disko Bay (Greenland) is limited. Environ. Pollut. 223, 73-80. https://doi.org/10.1016/j.envpol.2016.12.032.

Shemer, H., Linden, K.G., 2007. Aqueous photodegradation and toxicity of the polycyclic aromatic hydrocarbons fluorene, dibenzofuran, and dibenzothiophene. Water Res. 41, 853-861. https://doi.org/10.1016/j.watres.2006.11.022.

Smith, L.C., Stephenson, S.R., 2013. New Trans-Arctic shipping routes navigable by midcentury. Proc. Natl. Acad. Sci. Unit. States Am. 110, E1191-E1195. https:// doi.org/10.1073/pnas.1214212110. 
Starnawski, P., Bataillon, T., Ettema, T.J.G., Jochum, L.M., Schreiber, L., Chen, X., Lever, M.A., Polz, M.F., Jørgensen, B.B., Schramm, A., Kjeldsen, K.U., 2017. Microbial community assembly and evolution in subseafloor sediment. Proc. Natl. Acad. Sci. Unit. States Am. 114, 2940-2945. https://doi.org/10.1073/ pnas.1614190114.

Trzesicka-Mlynarz, D., Ward, O.P., 1995. Degradation of polycyclic aromatic hydrocarbons (PAHs) by a mixed culture and its component pure cultures, obtained from PAH-contaminated soil. Can. J. Microbiol. 41, 470-476. https://doi.org/ 10.1139/m95-063.

Vergeynst, L., Wegeberg, S., Aamand, J., Lassen, P., Gosewinkel, U., FrittRasmussen, J., Gustavson, K., Mosbech, A., 2018. Biodegradation of marine oil spills in the Arctic with a Greenland perspective. Sci. Total Environ. 626, 1243-1258. https://doi.org/10.1016/j.scitotenv.2018.01.173.

Wang, B., Lai, Q., Cui, Z., Tan, T., Shao, Z., 2008. A pyrene-degrading consortium from deep-sea sediment of the West Pacific and its key member Cycloclasticus sp. P1. Environ. Microbiol. 10, 1948-1963. https://doi.org/10.1111/j.1462-2920.2008. 01611.x.

Wang, H., Wang, B., Dong, W., Hu, X., 2016. Co-acclimation of bacterial communities under stresses of hydrocarbons with different structures. Sci. Rep. 6, 1-12. https://doi.org/10.1038/srep34588.

Wang, Z., Fingas, M., Blenkinsopp, S., Sergy, G., Landriault, M., Sigouin, L., Foght, J.,
Semple, K., Westlake, D.W.S., 1998. Comparison of oil composition changes due to biodegradation and physical weathering in different oils. J. Chromatogr. A 809, 89-107. https://doi.org/10.1016/S0021-9673(98)00166-6.

Wolfe, D.A., Hameedi, M.J., Galt, J.A., Watabayashi, G., Short, J., O'Claire, C., Rice, S. Michel, J., Payne, J.R., Braddock, J., Hanna, S., Sale, D., 1994. The fate of the oil spilled from the exxon valdez. Environ. Sci. Technol. 28, 560A-568A. https:// doi.org/10.1021/es00062a712.

Xie, W.H., Shiu, W.Y., Mackay, D., 1997. A review of the effect of salts on the solubility of organic compounds in seawater. Mar. Environ. Res. 44, 429-444. https://doi.org/10.1016/S0141-1136(97)00017-2.

Yakimov, M.M., Gentile, G., Bruni, V., Cappello, S., D'Auria, G., Golyshin, P.N., Giuliano, L., 2004. Crude oil-induced structural shift of coastal bacterial communities of rod bay (Terra Nova Bay, Ross Sea, Antarctica) and characterization of cultured cold-adapted hydrocarbonoclastic bacteria. FEMS Microbiol. Ecol. 49, 419-432. https://doi.org/10.1016/j.femsec.2004.04.018.

Yakimov, M.M., Giuliano, L., Gentile, G., Crisafi, E., Chernikova, T.N., Abraham, W.R. Lünsdorf, H., Timmis, K.N., Golyshin, P.N., 2003. Oleispira Antarctica gen. nov., sp. nov., a novel hydrocarbonoclastic marine bacterium isolated from Antarctic coastal sea water. Int. J. Syst. Evol. Microbiol. 53, 779-785. https://doi.org 10.1099/ijs.0.02366-0. 